Departamento de Ciência e Tecnologia, Secretaria de Ciência, Tecnologia e Insumos Estratégicos, Ministério da Saúde

Correspondência | Correspondence:

Decit - Departamento de Ciência e Tecnologia

do Ministério da Saúde

Esplanada dos Ministérios

Bloco G sala 845

70058-900 Brasília, DF, Brasil

Texto de difusão técnico-científica do

Ministério de Saúde.

\section{Informação científica para fortalecimento da gestão do Sistema Único de Saúde}

\author{
Scientific information for \\ strengthening the management of the \\ National Health System
}

A estruturação da área de ciência e tecnologia no âmbito do Ministério da Saúde (MS) teve como pedra fundamental a criação, em 2003, de uma secretaria dedicada ao tema: a Secretaria de Ciência, Tecnologia e Insumos Estratégicos (SCTIE). Desde então, a participação do ministério no investimento à pesquisa em saúde vem crescendo: a Secretaria apoiou, de 2003 a 2007, cerca de 2.500 pesquisas, totalizando um investimento de mais de R\$ 420 milhões.

Para viabilizar e aumentar esse aporte financeiro na área de ciência e tecnologia, foi firmado acordo de cooperação técnica com o Ministério da Ciência e Tecnologia, em 2004. Nesse acordo, o Conselho Nacional de Desenvolvimento Científico e Tecnológico (CNPq) e a agência Financiadora de Estudos e Projetos (Finep) tornaram-se agentes técnicos para as ações de fomento, com recursos orçamentários repassados em parceria pelos dois ministérios. As fundações de amparo à pesquisa (FAP), as secretarias estaduais de saúde (SES) e de ciência e tecnologia têm cooperado, regionalmente, para a operacionalização dos financiamentos de pesquisas voltadas para necessidades estaduais.

A SCTIE realiza duas modalidades de fomento - nacional e descentralizado - por meio da publicação de editais em temas prioritários para o Sistema Único de Saúde (SUS). Para projetos de âmbito nacional, foram destinados R\$ 296 milhões de 2003 a 2007, em diferentes áreas temáticas. Nesse período, houve também projetos nacionais financiados diretamente - devido a suas especificidades - que mobilizaram cerca de R $\$ 65$ milhões. Com relação ao fomento descentralizado - o "Programa Pesquisa para o SUS: gestão compartilhada em saúde" -, foram investidos mais de R\$ 60 milhões em todos os estados da Federação, contribuindo para a redução de desigualdades regionais na área de ciência e tecnologia em saúde.
Converter essa produção científica e tecnológica em contribuições para o SUS é, atualmente, uma das ações de destaque do MS no rol de suas políticas públicas. Na busca da aplicação sistemática dos resultados de pesquisas no planejamento e implementação das políticas de saúde, o MS tem por objetivo contribuir para que o SUS aperfeiçoe sua gestão e os serviços oferecidos à população, tornando esse sistema mais eficiente na execução de suas atribuições.

\section{PRODUÇÃO EDITORIAL: DIVULGANDO AÇÕES E RESULTADOS}

O trabalho de disseminação de informações realizado pelo Departamento de Ciência e Tecnologia (Decit) resulta em uma vasta produção editorial, disponível no portal da biblioteca virtual do MS. ${ }^{\mathrm{a}}$

Dois desses produtos merecem destaque. O primeiro é o Boletim Resultados de Pesquisas, destinado a gestores do SUS das três esferas governamentais e gestores de ciência e tecnologia, lançado pelo Decit em 2007. Seu objetivo é divulgar avanços e inovações alcançados com as pesquisas financiadas.

O segundo destaque são as matérias publicadas nas revistas de duas das mais prestigiadas instituições de pesquisa e ensino na área de saúde pública no Brasil - a Revista de Saúde Pública da Faculdade de Saúde Pública da Universidade de São Paulo e Cadernos de Saúde Pública da Escola Nacional de Saúde Pública Sergio Arouca da Fiocruz -, cujo objetivo é divulgar as ações do Decit para o público acadêmico.

O Decit financiou, ainda, a edição dos livros: "Saúde no Brasil: Contribuições para a Agenda de Prioridades de Pesquisa"; "Pesquisa para Saúde: Contribuições aos 20 
anos do SUS"; "Aborto e Saúde Pública no Brasil: 20 Anos"; "20 Anos de Pesquisas sobre Aborto no Brasil" e , no prelo, Pesquisa Nacional de Demografia e Saúde da Criança e da Mulher (PNDS-2006).

O primeiro, lançado, em 2004, durante a II Conferência Nacional de Ciência, Tecnologia e Inovação em Saúde (CNCTIS), reúne textos sobre diversos aspectos da situação da saúde e das políticas do setor no Brasil, encomendados a especialistas por ocasião da construção da Agenda. Devido à qualidade e abrangência de seu conteúdo, o livro passou a ser considerado um marco fundamental no processo político que culminou na aprovação da Agenda.

Publicado em 2008, o livro "Pesquisa para Saúde: contribuições aos 20 anos do SUS" contém um catálogo com informações sobre pesquisas financiadas e avaliadas pelo Decit, de 2003 a 2007. Traz, também, dez artigos que ilustram a contribuição científica para o SUS.

Os dois títulos sobre o aborto resultaram de um projeto de pesquisa que sistematizou 20 anos de publicações sobre o tema no Brasil. Para sua elaboração foram recuperadas e avaliadas 2.109 fontes em língua portuguesa que tratam do assunto. Foram selecionadas aquelas que indicavam conter pesquisas com dados primários ou secundários para uma análise posterior integral. Por fim, foram examinadas em profundidade 398 fontes bibliográficas, que correspondem ao universo dos estudos com evidências.

Essas fontes são apresentadas, nas duas publicações, ordenadas por títulos temáticos que remetem às principais questões de pesquisa sobre aborto no País e aos desafios da saúde pública impostos pela ilegalidade dessa prática. A diferença entre os dois livros, ainda inéditos, é que em um deles ("20 anos de pesquisas sobre aborto no Brasil"), a relação das fontes está disponível em CD-ROM e no outro está na forma impressa. Ambos serão lançados em 2009.

Outra pesquisa financiada pelo Decit que resultou em livro é a Pesquisa Nacional de Demografia e Saúde da Criança e da Mulher (PNDS-2006). A publicação, com lançamento previsto, também, para 2009, reúne 15 artigos sobre os diferentes temas abordados. Um deles explica os aspectos metodológicos adotados e como proceder para comparar dados de pesquisas de demografia e saúde realizadas anteriormente.

\section{CONTRIBUIÇÃO DO TRABALHO EM REDE}

Para ampliar a disseminação das ações do MS, o Decit tem estreitado laços com as diversas áreas técnicas do Ministério da Saúde. Essa parceria está resultando, por exemplo, na estruturação da Rede Nacional de Pesquisa em Saúde Mental. A rede tem como objetivo a articulação entre pesquisadores, gestores, profissionais e usuários da área de saúde mental pública para desenvolver pesquisas e disseminar resultados que preencham as lacunas de conhecimento da área.

A consolidação do trabalho de disseminação da informação científica realizado pelo Decit fez com que o Departamento fosse convidado a participar da Evidence-Informed Policy Network (EVIPNet), uma rede de iniciativa da Organização Mundial de Saúde que já existe nos continentes africano e asiático e está se estruturando nas Américas. Essa rede tem como objetivos levantar as grandes questões da saúde pública, sistematizar o conhecimento existente para atender às suas necessidades e promover o uso de evidências científicas para tomada de decisões. 